\title{
त्री \\ A revolução darwiniana na paleontologia e a ideia de progresso no processo evolutivo
}

Felipe FARIA

\begin{abstract}
茴
RESUMO

A ideia da existência de uma tendência dos organismos ao progressivo aumento de complexidade da organização corporal já se fazia presente em tempos anteriores ao evolucionismo. Com a aceitação das teorias evolutivas, vários naturalistas, e especialmente aqueles que trabalhavam com fósseis, passaram a defender a ocorrência de tal tendência no processo evolutivo. Essa nova forma de abordar a ideia de progresso na natureza recebeu várias interpretações até o momento do surgimento da síntese evolutiva moderna, que pouco espaço deixou para a existência de outro elemento orientador da evolução, que não fosse aquele proposto por Darwin.
\end{abstract}

Palavras-Ghave • Progresso. Complexidade. Organização corporal. Evolução. Fósseis.

\section{INTRODUÇÃO}

Os impactos do processo que ficou conhecido como revolução darwiniana repercutiram em diversos campos do conhecimento humano, principalmente em áreas como as ciências que estudam ou utilizam dados sobre a história da vida. Elas tiveram seus objetivos cognitivos rapidamente transformados em função da introdução do evolucionismo como fator orientador das pesquisas e, mediante essa situação, iniciou-se uma busca por evidências que apoiassem as hipóteses elaboradas sob essa nova orientação.

Mesmo não havendo um consenso sobre a ocorrência de um processo revolucionário no âmbito das diversas áreas que compõem as atuais ciências biológicas, como citado por Thomas Kuhn (1962, p. 20, 150, 170, 171), é impossível negar as grandes transformações sofridas por essas áreas do conhecimento que, apesar de já estarem em andamento, receberam um enorme impulso com a publicação das teorias de Charles Darwin, em seu livro de 1859 (cf. Bowler, 1976, p. 12; 1983, p. ix-x; 1996, p. 14-6; Mayr, 1998, p. 559-65, 988; Rudwick, 2005, p. 7; Ruse, 2009, p. 104,0).

Particularmente, no âmbito da paleontologia, instaurada como ciência através da aceitação dos trabalhos de naturalistas, tais como, por exemplo, Georges Cuvier (1769-1832), novos objetivos cognitivos foram incorporados quando os paleontólo- 
gos passaram a orientar seus estudos sob a luz do evolucionismo (cf. Caponi, 2004, p. 251-8; Faria, 2012, p. 229-49). Um desses objetivos, a busca por fósseis que completassem as genealogias dos organismos participantes da história da vida na Terra, foi intensamente levado adiante, desde a aceitação da teoria da unidade de tipo por filiação comum, proposta na Origem da espécies. ${ }^{\mathbf{1}}$ Entretanto, muitos estudiosos dos fósseis permaneceram cumprindo os objetivos cognitivos do programa de pesquisa proposto por Cuvier, o qual objetivava alcançar a compreensão fisiológica dos seres vivos e extintos, utilizando-a como critério para a classificação taxonômica, formando um único sistema. Tal objetivo foi superado pelo novo programa de pesquisa, quando este visou o estabelecimento de genealogias entre os seres vivos e extintos, as quais, por sua vez, serviam como critério para a classificação taxonômica.

Para atingir a compreensão das possíveis formas de organização corporal existentes na natureza, que é o principal objetivo cognitivo do programa de pesquisa cuvieriano, os naturalistas sob essa orientação procuravam determinar e classificar o maior número possível de organismos, inclusive fósseis. $\mathrm{O}$ aumento contínuo do rol das formas possíveis de organização corporal contribuía diretamente para a aplicação do método que possibilitava o cumprimento daquele programa de pesquisa. Somente após o emprego do método anátomo-comparativo, os organismos fósseis puderam ser reconstruídos e, consequentemente, determinados taxonomicamente. Nesse processo, eles, circularmente, também serviam como elementos de comparação, uma vez que, aumentando o rol das formas de organização corporal conhecidas, incrementava-se também o poder exploratório da comparação. Após serem comparados, os fósseis podiam ser classificados taxonomicamente em um sistema que os situava, pela primeira vez, em conjunto com os seres viventes, formando um sistema único de classificação taxonômica, capaz de abranger todo o estoque do mundo natural. Era uma inovação no âmbito da história natural, pois até aquele momento os fósseis, devido às poucas informações que proporcionavam sobre a morfologia dos organismos que os originavam, apresentavam grandes dificuldades para uma classificação lineana, baseada principalmente nas características morfológicas.

Esse foi um avanço que mais tarde serviu também aos evolucionistas, porque as determinações taxonômicas dos organismos fósseis, feitas pelos naturalistas de orientação cuvieriana, passaram a ser utilizadas na composição das sequências filéticas que os evolucionistas propunham, para indicar a ocorrência do processo evolutivo no desenrolar da história da vida na Terra (cf. Caponi, 2011, p. 122). Na análise das sequên-

1 “(...) Por unidade de tipo entende-se aquela concordância fundamental de estrutura, que observamos nos seres organizados pertencentes à mesma classe, a qual independe inteiramente de seus hábitos de vida. Pela minha teoria, a unidade de tipo é explicada por unidade de descendência” (Darwin, 1859, p. 206). 
cias, alguns evolucionistas perceberam que diversos grupos taxonômicos incrementavam a complexidade de sua organização corporal ao longo do tempo e, assim, eles passaram a defender que havia um elemento de progressividade conduzindo a história da vida e da Terra. Essa questão já vinha sendo discutida muito antes da publicação do livro Origem das espécies, e recebeu um relativo impulso durante o processo de aceitação dos métodos e do programa de pesquisa de Cuvier, fundamentais na instauração da paleontologia como ciência. As inúmeras descobertas de fósseis, fomentadas pelo programa de pesquisas cuvieriano, resultaram na formulação de várias hipóteses explicativas dos fenômenos e processos envolvidos na história da vida e da Terra e, entre elas, constavam hipóteses baseadas na existência de um elemento direcional conduzindo esses fenômenos no sentido de um aumento da complexidade (Bowler, 1976, p.18-20; Rudwick, 2008, p. 448-9).

Para os cuvierianos, esse aumento estava relacionado exclusivamente com a complexidade da organização corporal dos seres estudados. Até mesmo a cronologia de seus surgimentos nas camadas geológicas era apenas um indicativo do momento em que o referido aumento se dera. Entretanto, após a mudança do programa de pesquisa, sofrida pela paleontologia quando da aceitação das teorias evolutivas, o fator cronológico, por exemplo, recebeu uma nova abordagem. Ele se tornou importante para o estabelecimento das relações genealógicas, o objetivo cognitivo do novo programa.

Juntamente com essas mudanças, a própria ideia de uma tendência ao aumento da complexidade também foi alterada no decorrer das discussões que se seguiram à aceitação das teorias evolutivas. Não só a inclusão do fator cronológico, mas também outras questões foram colocadas, como, por exemplo, se haveria tendências à progressividade nas sequências evolutivas paralelas de organismos relacionados taxonomicamente, ou se o referido aumento de complexidade poderia ser orientado durante o desenvolvimento embriológico. Tais questionamentos e suas consequências deverão ser analisados neste artigo, relacionando-os ao desenvolvimento da paleontologia e às diversas teorias evolutivas que orientaram os trabalhos de vários paleontólogos. Tal análise levará em consideração as mudanças que a ideia de progresso sofreu ao longo dessa trajetória, até a profunda alteração de sentido produzida pela síntese moderna evolutiva.

\section{O PROGRESSO COMO FENÔMENO NATURAL}

Sem ser explícito, Cuvier abordou esse assunto ao defender que, ao longo da história da vida, houve um processo sucessório de faunas compostas por seres cada vez mais assemelhados aos atuais (cf. Cuvier, 1812a, p. 68-73; 183o, p. 112-21). Entretanto, essa defesa não implicou uma sustentação ostensiva da existência de um progressivo au- 
mento de complexidade das formas de organização corporal durante a história da vida na Terra. Para Cuvier, o surgimento dos organismos vivos ocorrera em um único momento, e não de forma progressiva, ou seja, todas as formas possíveis, simples ou complexas, manifestaram-se ao mesmo tempo.

Ao longo do tempo, esse imenso rol de formas de organização corporal ia sendo reduzido, pois vários desses seres vivos iam se extinguindo, deixando como vestígios de sua existência somente seus fósseis. Em sua teoria das revoluções, Cuvier defendia que essas extinções aconteciam em função da ocorrência de fenômenos catastróficos, de ação local e não universal. Inundações, vulcões, terremotos etc. eram fenômenos geológicos que ocorriam de forma súbita, transformando a configuração geológica do local, atingido e fazendo desaparecer as faunas e floras que ali viviam. Após o evento, animais e vegetais provenientes dos locais não atingidos migravam e ocupavam a localidade que apresentava uma nova configuração geológica. Essa sucessão biológica podia ser verificada por meio do registro fossilífero e, se analisada sob a luz de outras teorias, como, por exemplo, a teoria das criações sucessivas, ou ainda, das ideias transformistas existentes na época de Cuvier, como as defendidas por Jean-Baptiste Lamarck (1744-1829), poderia sugerir uma tendência de direcionalidade progressiva ocorrendo na história da vida na Terra.

Quando o acúmulo de conhecimentos sobre as catástrofes cuvierianas levou a um aumento na contagem dessas revoluções, ficou difícil explicar como um único estoque biológico primordial podia dar conta de tantas baixas. Para resolver essa questão alguns naturalistas cuvierianos, como Alcide D’Orbigny (1802-1857), Louis Agassiz (1807-1873) e outros, defenderam que, ao invés de ter sido submetida a um único evento de criação, a Terra havia sido ocupada por faunas e floras criadas após cada evento extintivo. Era a teoria das criações sucessivas que, segundo alguns naturalistas, como Agassiz, por exemplo, além de explicar a diversidade pretérita e atual, também indicava haver um aumento do grau de complexidade corporal ao longo do tempo. No processo de sucessão, os organismos, que iam surgindo, aumentavam progressivamente o grau de complexidade de suas formas de organização corporal, conduzindo-as ao seu mais alto nível, que seria a forma humana (cf. Jameson, 18०8, p. 82; Cuvier, 1812b, p. 6; Chambers, 184,6, p. 263). Como exemplo dessa situação, James Parkinson (1755-1824) escreveu em 1811, após discorrer sobre a sequência de ocupação do ambiente terrestre, "a criação do homem, fomos informados, foi o trabalho do último período" (Parkinson, 1811, p. 450-1). A mesma opinião era compartilhada por Robert E. Grant (1793-1874) ao escrever que "encontramos com a mais perfeita classe de animais, somente nas camadas recentes de rochas, e as mais perfeitas, aquelas intimamente relacionadas com a nossa própria espécie, somente nas [camadas] mais recentes" (Grant, 1826, p. 295-7). 
Em sua defesa da teoria das criações sucessivas, Louis Agassiz também defendia que na sucessão das formas orgânicas havia um padrão indicando a existência de um aumento de complexidade direcionado, que surgia nos peixes e ia até o homem (cf. Agassiz, 1853, p. 237-8; 1962 [1857], p. 108-9). Havia nessa proposição um resgate da ideia da manifestação de uma "escala de seres", ligando todas as formas em um plano de crescente complexidade de organização corporal.

Lamarck havia utilizado essa ideia de série escalar na formulação de sua teoria transformista, mas em sua defesa fez pouca referência à sucessão biótica de grandes grupos taxonômicos, como classes e ordens, defendida por Cuvier. A sucessão nesse nível foi primeiramente utilizada como argumento por naturalistas de orientação fixista que, apesar das divergências com as ideias evolutivas de Lamarck, consideravam existir na natureza uma tendência conduzindo à manifestação das formas ao longo do tempo na direção de um ponto máximo, onde invariavelmente se encontrava o homem (cf. Lovejoy, 1964, p. 227-41).

Por sua vez, o catastrofismo considerava ter havido uma trajetória direcional na sucessão dos organismos, mas sem a existência de um elemento de progressividade orientando a história da vida. Na sucessão biótica defendida pelos cuvierianos, as faunas mais assemelhadas à atual, em termos de organização corporal, sucediam, ao longo do tempo, às menos assemelhadas. Isso ocorria sem que nenhum organismo extinto reaparecesse, havendo nessa sucessão uma direcionalidade que não implicava aumento de complexidade, mas apenas de semelhança com as formas atuais.

Para chegar a tal conclusão, Cuvier se baseara nas sequências de estratos geológicos e de seu conteúdo fossilífero, da mesma maneira que Charles Lyell (1797-1875) fez a partir da terceira década do século XIX. Entretanto, as conclusões de Lyell promoveram uma "reforma" da geologia, trazendo de volta a busca pelas causas dos fenômenos observados (cf. Lyell, 183o, p. 75-91; 1833, p. 1-8). Tratava-se de uma busca que Cuvier havia lutado para expurgar dos objetivos cognitivos da geologia. Nessa reforma, Lyell também se opôs à teoria catastrofista, propondo que a configuração geológica e biológica atual resultava de transformações ocorridas de forma lenta e gradual, e não através de eventos pontuais e súbitos, como os catastrofistas defendiam.

Mas para tanto foi necessária a admissão de uma antiguidade da Terra extremamente longa, capaz de acomodar a enorme quantidade de tempo demandada para a ocorrência dos lentos processos que resultaram na configuração biológica e geológica atual. Cuvier já havia aberto o espaço para essa discussão quando clamou a necessidade de "romper os limites do tempo", que impossibilitavam uma adequada acomodação temporal dos eventos que os registros geológico e fossilífero indicavam ter ocorrido (Cuvier, 1812a, p. 3). O acúmulo do conhecimento sobre estes registros fez aumentar ainda mais a concepção de um "tempo profundo", que serviu para Lyell como base de 
argumentação em defesa de sua teoria atualista, conhecida como uniformitarismo. Os caracteres de lentidão e gradualismo da teoria lyelliana demandavam esse tempo profundo, para que os lentos e graduais processos geológicos pudessem ocorrer e, assim, ela recebeu adesão de grande parte da comunidade científica, mesmo que a extrema aplicação do princípio atualista, um dos pontos centrais da teoria, tenha sido rejeitada (cf. Whewell, 1832, p. 104, 126).

A extrema aplicação do princípio atualista, requerida pela teoria uniformitarista, não foi bem recebida pelos naturalistas ainda influenciados por explicações catastrofistas, dado que criticavam a invariabilidade da intensidade dos fenômenos geológicos, que era um dos pontos principais do uniformitarismo. Para Lyell, não havia nenhuma diferença entre a intensidade dos eventos atuais e a dos pretéritos. As transformações geológicas e biológicas teriam ocorrido na história da Terra de forma lenta e gradual, sem que houvesse a ocorrência de nenhum evento súbito e catastrófico. Lyell aplicou, de maneira extrema, o princípio atualista, fundamental para a formulação das ideias de Darwin, que também considerava que as mudanças no mundo natural ocorriam de forma lenta e gradual.

Mas, nas décadas antecedentes à publicação de Origem das espécies, os defensores remanescentes do catastrofismo questionaram o gradualismo requerido por Lyell e Darwin. Agassiz começou sua carreira propondo que a sequência faunística manifestava-se através de "criações sucessivas". Estas ocorriam descontinuamente através do cumprimento de um "plano de criação", que era a manifestação do "pensamento de Deus" (Agassiz, E., 1885, p. 395-6; cf. Bowler, 1976, p. 50). Porém, com o incessante acúmulo de novas descobertas e as discussões que se seguiram à publicação da teoria evolucionista de Darwin, ele arrefeceu e passou a considerar que as descontinuidades, perceptíveis no registro fossilífero, não eram tão marcantes quanto já havia defendido (cf. Agassiz, 1833, p. 169-71).

Mediante os avanços da paleontologia, Agassiz se viu forçado a elaborar uma nova explicação para as evidências, apontando para uma continuidade na sucessão biológica, a qual era utilizada pelos evolucionistas na elaboração das sequências filogenéticas. Refutando o evolucionismo e baseando-se em dados da embriologia, Agassiz defendia haver um "paralelismo" entre o desenvolvimento embriológico e a sequência de classes de vertebrados constante no registro fossilífero. Ele propunha que desde que o contínuo desenvolvimento embriológico fosse o cumprimento de algum "plano de criação”, a sucessão das classes de vertebrados também poderia ser interpretada da mesma maneira e, além disso, que existiam ramos laterais desse plano, representando suas variações (cf. Agassiz, 1859, p. 178-85; 1962 [1857], p. 110-5; Bowler, 1976, p. 52).

Esse paralelismo entre o desenvolvimento filogenético e o embriológico também foi utilizado por naturalistas em sua busca de evidências do processo evolutivo. 
Quando os evolucionistas não encontravam no registro fossilífero as evidências indicativas de suas hipóteses filogenéticas, ou seja, não conseguiam completar suas sequências evolutivas, podiam voltar-se às evidências proporcionadas pelos estudos da embriologia. Segundo Peter Bowler, “onde a evidência fossilífera falhava, a embriologia e a anatomia comparada eram utilizadas para prover os elos hipotéticos entre as formas conhecidas" (1976, p. 129; 1996, p. 12-4).

Assim fizeram vários naturalistas, e também Robert Chambers (1802-1871) no livro em que divulgou suas ideias evolutivas, Vestígios da história natural da criação, de 1844 (p. 191-235; Bowler, 1976, p. 57). Chambers defendia a existência de um elemento de progressão ditando a história da vida, que ele percebia em sua análise de sequências evolutivas elaboradas com os dados provenientes do registro fossilífero. Contudo, havia algumas dessas sequências que, para serem completadas, necessitavam da utilização de evidências advindas da embriologia, como no caso da sequência que estabelecia a origem dos vertebrados. Para suprir a falta de formas transicionais entre os invertebrados e os vertebrados, Chambers propunha que elas pudessem ser virtualmente substituídas com base na semelhança que havia entre a estrutura morfológica de invertebrados fósseis e a carapaça externa de vertebrados, como os peixes silurianos, ${ }^{2}$ e entre a morfologia primitiva da cauda desses peixes e o estágio embrionário dos peixes atuais. Segundo ele, essa semelhança evidenciava tal transição e permitia elaborar uma sequência evolutiva, que apontava para um aumento de complexidade da organização corporal (cf. Chambers, 1844, p. 63, 69, 71).

O impacto da obra de Chambers deve ser mensurado pela geração das discussões que provocou, e não pela exposição das evidências favoráveis ao evolucionismo (cf. Bowler, 1983, p. 26). O Vestígios da história natural da criação divulgou, anonimamente, as ideias de um editor de publicações científicas, que utilizou o grande acesso que tinha aos trabalhos científicos para posicionar-se e formular hipóteses evolutivas, mesmo sem propor um mecanismo evolutivo inteligível (cf. Chambers, 1846, p. 21-3). Independentemente dessa ausência e levando em consideração o elemento de aleatoriedade contido na teoria da seleção natural, o próprio Darwin comentou que as discussões geradas pelo livro de Chambers tiveram a capacidade de preparar sua argumentação em defesa de suas próprias ideias, porque tiveram eminentes debatedores naturalistas, como Adam Sedgwick (1785-1873), Agassiz, entre outros (cf. Darwin, 1845, 1854; Sedgwick, 1845).

Mesmo não participando desse debate, Darwin utilizou, como Lyell fizera em defesa do uniformitarismo, uma abordagem atualista para formular e expor o seu mecanismo evolutivo, fazendo uma analogia com a prática da seleção artificial, executada 
há milênios por criadores de plantas e animais. Só então ele passou a tratar da questão das falhas do registro fossilífero, as quais poderiam levantar dúvidas sobre a existência de um processo evolutivo agindo lenta e gradualmente, como ele propunha. As dinâmicas biológica, geológica e tafonômica ${ }^{3}$ foram utilizadas como forma de explicar a falta de preservação de muitos elos transicionais das sequências filogenéticas propostas.

No que concerne a essas discussões sobre as falhas do registro fóssil, cabe ressaltar a importância do nível taxonômico em que se tentava estabelecer o sequenciamento filogenético. Na composição das sequências filogenéticas de grandes grupos taxonômicos, como, por exemplo, na evolução dos dinossauros para as aves, apenas alguns fósseis bastaram para convencer grande parte da comunidade científica da existência de estruturas transicionais em fósseis dos dois grupos. Um dos grandes defensores do evolucionismo, Thomas Huxley (1825-1895), utilizou com sucesso, em defesa do estabelecimento da sequência evolutiva das aves, apenas os fósseis do Archaeopterix e do Compsognathus, que apresentavam mutuamente características morfológicas dos dois grupos (cf. Huxley, 1868; Owen, 1864, p. 45-7; Wagner, 2003 [1861], p. 274).

Quando a oportunidade surgiu, ele intensificou esse tipo de utilização aproveitando o aporte de dados que as descobertas paleontológicas produziam em um ritmo crescente. Entre estas, um grupo taxonômico em especial começou a prover os evolucionistas de uma abundância de fósseis, que podiam ser utilizados na elaboração de uma sequência evolutiva mais completa. Aproveitando as várias descobertas de fósseis de equídeos, feitas na Europa e na América do Norte desde a década de cinquenta do século xix, Huxley elaborou uma filogenia dos cavalos e passou a utilizá-la como mais um argumento em defesa do evolucionismo. Segundo ele, a teoria mais adequada para interpretar o processo evolutivo fora proposta por Darwin, uma vez que os dados paleontológicos, como esses que se referiam aos cavalos, indicavam que as causas da evolução não eram consistentes com a progressão (cf. Huxley, 1896a [1862], p. 298, 3०3-4).

\section{A IDEIA DE PROGResso NA SEQUÊNGIA EVOLUTIVA DOS EQUídeos}

Huxley duvidava da existência de qualquer tendência a um aumento progressivo de complexidade ocorrendo na história evolutiva dos organismos, porque defendia que havia "tipos persistentes", mantenedores de suas formas de organização corporal ao longo dos tempos, ou, em outras palavras, defendia que havia uma tendência à manutenção da unidade de tipo (Huxley, 1896a [1862], p. 292). Para superá-la, a evolução atuava nesses tipos persistentes, assim como em todos os organismos, de forma lenta e gra- 
dual. Era o que havia ocorrido com os cavalos e, segundo alguns evolucionistas, a evolução desse grupo poderia ser evidenciada com o estudo de seus fósseis. Assim fez Albert Gaudry (1827-1908), escavando os estratos do Mioceno4 da região de Pikermi, na Grécia, onde descobriu fósseis que apresentavam características intermediárias entre mamíferos da época anterior e posterior àquela. Entres esses havia fósseis de um gênero de equídeos denominado Hipparion, que, por sua abundância, permitiram a Gaudry estudar a existência de uma grande amplitude e continuidade variacional, dentro de um mesmo grupo taxonômico. Tal estudo possibilitou o estabelecimento dos limites da variabilidade, porque contou com um grande número de espécimes, com os quais melhores comparações anatômicas podiam ser realizadas (cf. Gaudry, 1862, p. 22533). A constatação desses limites provia suporte ao evolucionismo, uma vez que aprimorava o processo de determinação das espécies, facilitando, assim, o estabelecimento de relações genealógicas entre elas.

Entretanto, apesar dessa contribuição ao evolucionismo, Gaudry não defendia as teorias de Darwin, por entender que o componente acidental requerido por elas não era condizente com a harmonia imperante no mundo natural. Para ele, a natureza era operada pelo Criador de acordo com um plano capaz de refletir a harmonia da criação (cf. Gaudry, 1862, p. 367-70; 1878, p. 257-9; 1896, p. 200-8). Com essa proposição, Gaudry se aproximava de uma escola de pensamento evolucionista, que defendia um papel fundamental para Deus no processo de evolução, seja como seu precursor ou operador. Era o evolucionismo teísta, que tinha entre seus defensores aqueles que consideravam haver um aumento progressivo da complexidade corporal dos organismos surgidos a cada evento criativo, uma vez que esse processo era dirigido ao alcance da perfeição, por ser operado pela divindade superior (cf. Bowler, 1983, p. 44-57; Conry, 1974, p. 222).

Baseado em tais convicções evolucionistas e teístas, Gaudry inclinou-se a defender uma sequência evolutiva, relacionando através das épocas geológicas o Hipparion e os cavalos. Até a descoberta do fóssil desse animal do Mioceno superior, o grupo dos equídeos permanecia isolado taxonomicamente, não sendo estabelecida, até então, nenhuma relação com o grupo dos ungulados com número impar de dedos, os perissodátilos. Entretanto, o Hipparion, um animal muito similar aos cavalos, apresentava dedos laterais, os quais para Gaudry eram uma característica intermediária entre este e o grupo taxonômico do Anchitherium, um primitivo ungulado do Mioceno inferior, o qual já havia sido descrito por Cuvier em 1825, como Palaeotherium, e depois separado genericamente, em 1844, por Hermann von Meyer (1801-1869) (cf. Gaudry, 1862, p. 353-5; Alberdi et al., 2004, p. 116).

4. Mioceno: época geológica compreendida entre 24 e 5,3 milhões de anos. 
Mas apesar de ser conclusivo quanto a essa relação, Gaudry não incluiu o Anchitherium no diagrama que propôs para a evolução dos equídeos, limitando-se a indicar a relação evolutiva que havia entre os gêneros do Hipparion e dos cavalos. Todavia, ainda assim, esse diagrama da evolução dos equídeos foi uma inovação na representação visual do processo evolutivo, uma vez que o próprio Darwin havia utilizado esse recurso somente de forma esquemática (cf. Darwin, 1859, p. 116; Gaudry, 1862, p. 354).

Com a clareza demonstrada pelo diagrama, e pelos dados produzidos nos estudos de Gaudry, o naturalista russo Wladimir Kovalevsky (1842-1883) pôde fazer mais avanços na reconstrução da filogenia dos equídeos. Segundo Kovalevsky, o estudo de Gaudry era "o melhor trabalho paleontológico surgido na França, desde o Investigações sobre as ossadas fósseis de quadrúpedes (1812), de Cuvier"5 e representava uma nova tendência de trabalhos que "objetivavam uma completa investigação da osteologia dos gêneros extintos e de suas afinidades com os viventes". Tal tendência havia sido iniciada com a aceitação da teoria de Darwin, que estava "projetando nova luz sobre as pesquisas paleontológicas" (Kovalevsky, 18ך3, p. 20).

Orientado pela nova luz, Kovalevsky fez descrições e comparações anatômicas entre diversas espécies fósseis e viventes da linhagem dos ungulados e propôs uma sequência evolutiva, baseada no mecanismo da seleção natural, que relacionava os cavalos, o Hipparion, o Anchitherium e o Palaeotherium (cf. Kovalevsky, 1873, p. 53). Segundo ele, os cavalos poderiam ser considerados como descendentes modificados de uma forma ancestral que se havia modificado ao longo do tempo, mas sem alterar sua estrutura típica. Isso ocorreu devido às condições de vida a que foram submetidos, as quais também se alteraram com o decorrer do tempo (cf. Kovalevsky, 1873, p. 65).

Dando ênfase às transformações da osteologia dos membros desses animais, que tiveram o número de dígitos reduzido ao longo da sequência, Kovalevsky fez correlações entre essa redução e as respostas que produziram as exigências das particularidades do entorno, para adaptarem-se ao surgimento de novos ambientes campestres. Com a irradiação das gramíneas durante o Mioceno, novos ambientes foram formados, com aquela nova composição vegetal resultando na formação de grandes territórios abertos, onde um grupo de ungulados, os perissodátilos, desenvolveu um hábito cursor diferente, uma hipótese considerada até os dias de hoje (cf. Wang et al., 1994, p. 277-8; Eronen et al., 2009, p. 4,06). Com a redução do número de dedos que se apoiavam no chão, de três, em cada membro do Palaeotherium, para somente um, nos cavalos, houve um incremento na capacidade locomotora, refletindo, assim, melhores con-

5 Nesta obra, Cuvier compilou seus trabalhos paleontológicos, executados desde 1796, apresentando seu programa de pesquisa para o estudo dos fósseis. Ela se tornou a principal obra de divulgação de suas ideias. Em 1825, teve seu discurso preliminar desmembrado e publicado à parte como Discours sur les révolutions sur la surface du Globe (Discurso sobre as revoluções da superfície do Globo), que sucedeu o Ossemens Fossiles, como obra de divulgação de Cuvier. 
dições na luta pela sobrevivência nas grandes pradarias formadas a partir do sucesso evolutivo das gramíneas (cf. Kovalevsky, 1873, p. $7^{3}$ ).

Era uma hipótese darwiniana, que Huxley prontamente utilizou como mais um argumento em sua defesa do evolucionismo. Em 1873, ele leu um trabalho de Kovalevsky em uma sessão da Royal Society of London (Sociedade Real de Londres), que estabelecia as relações evolutivas dos ungulados, baseadas em fósseis desse grupo encontrados em solo europeu. Por meio das sequências evolutivas propostas por Kovalevsky e Gaudry, alguns evolucionistas passaram a defender que os equídeos tiveram sua origem na Europa.

Foi o que Huxley fez até 1876, quando em viagem aos Estados Unidos da América tomou conhecimento de uma hipótese alternativa, proposta por Othniel Charles Marsh (1831-1899). Marsh desenvolvia um estudo sobre equídeos fósseis da América do Norte e propunha uma sequência evolutiva de seis estágios relacionando o ungulado eocênico ${ }^{6}$ com quatro dígitos nos membros posteriores, Orohippus, ao cavalo moderno, o Eqqus, passando pelo Hipparion (cf. Huxley, 1893 [1876], p. 129-32). Para Huxley aquela sequência era uma "evidência demonstrativa da evolução", principalmente se fosse estendida até o fóssil recém descoberto por Marsh, o Eohippus. Com a introdução desse fóssil era possível defender a origem americana dos equídeos, porque o Eohippus era mais antigo do que os fósseis de equídeos europeus. Além disso, essa forma remota apresentava um quinto dígito vestigial nos membros posteriores, que possibilitava relacionar evolutivamente a linhagem dos equídeos à dos mamíferos, cujo hipotético tipo basal deveria apresentar a conformação pentadáctila (cf. Marsh, 1879, p. 504; Huxley, 1893 [1876], p. 129-32).

A manutenção dessa anatomia basal dos membros, até o desenvolvimento da linhagem dos equídeos, era resultante de sua adaptação ao ambiente vegetal que habitavam, o qual era composto por florestas. Quando ocorreram as transformações ambientais no Cenozóico, houve a formação de grandes pradarias, que seriam ocupadas pelo grupo taxonômico que originaria os equídeos. A resposta adaptativa a essa condição foi a evolução de um aparelho motor capaz de atingir grandes velocidades, necessárias para escapar da predação. Entretanto, ao ocuparem o novo ambiente, a dieta dos equídeos também foi alterada, porque passaram a alimentar-se das gramíneas ao invés das tenras folhas existentes no ambiente florestal, no qual as patas polidátilas se faziam eficientes para o bom deslocamento. Em resposta às exigências do novo ambiente, sua dieta foi alterada e sua dentição passou a sofrer um desgaste muito maior, uma vez que, no forrageio, os animais também ingeriam materiais abrasivos, como, por exemplo, grãos de areia, além das espículas de sílica constituintes das próprias folhas das gramíneas. 
A resposta adaptativa do grupo ocorreu com a evolução de uma dentição mais resistente ao desgaste e com uma anatomia dental mais propícia à mastigação do novo material, que era requerido em maiores quantidades, uma vez que seu valor nutricional era menor do que o das tenras folhas das árvores e dos arbustos. A evolução de dentes com coroas mais altas (hipsodontia), com camadas mais espessas de esmalte e apresentando encaixes mais eficientes para a oclusão, permitiram que o grupo se alimentasse sem que isso representasse algum prejuízo das suas condições na luta pela sobrevivência no novo ambiente que passavam a ocupar, porque os dentes permitiram um melhor aproveitamento da nova dieta, ao tornarem-se mais oclusivos e mais resistentes (cf. Kovalevsky, 1873, p. 67; Huxley, 1893 [1876], p. 119-23; Simpson, 1951, p. 1819; Eronen et al., 2009, p. 4,06).

Mesmo parecendo haver algum elemento de progressividade na sequência evolutiva que Huxley passou a defender, ele suspeitava dessa ideia, uma vez que defendia que, no processo evolutivo, havia uma tendência à "persistência do tipo", ou seja, à permanência de formas similares durante longos períodos de tempo. Era sua visão da ideia de unidade de tipo proposta por Darwin, constatável com a análise do registro fóssil, o qual também exibia vários exemplos do surgimento de ancestrais com organizações corporais ainda mais complexas do que a de seus descendentes (cf. Huxley, 1896a [1862], p. 292-303). Entretanto, Huxley, de maneira similar a Marsh, passou posteriormente a considerar que, durante o processo evolutivo, poderia haver algum tipo de tendência a um aumento de especialização da estrutura (cf. Huxley, 1863, p. 128; 1896b [1870], p. 358-9).

Evitando ser explícito com relação a essa tendência progressionista, dado que a mesma podia levar a uma interpretação teísta do evolucionismo, Huxley procurou estabelecer "leis da evolução", que conduziam os tipos de especialização que ocorriam nos processos evolutivos, nesse caso, a redução dos dígitos, capazes de transformar o Eohippus nos modernos cavalos (cf. Huxley, 1902 [1880] p. 458-9). Marsh já havia postulado uma "lei do crescimento cerebral", estabelecendo que o aumento no tamanho do cérebro, ocorrente nas sequências evolutivas dos ungulados, era uma consequência da seleção natural (cf. Marsh, 1886, p. 58-9). Apesar de não considerá-lo como uma garantia da existência de uma tendência ao progressivo incremento de complexidade, a lei de Marsh, assim como a de Huxley, serviu aos progressionistas, visto que estes consideravam que o aumento cerebral e a redução dos dígitos dos equídeos eram indícios de um aumento de complexidade organizacional, na medida em que o aumento ocorrera progressivamente em um único sentido, ou seja, sem o surgimento, ou retorno, de formas menos complexas.

Marsh aplicou sua lei em um trabalho no qual tratou da origem dos ungulados e dos mamíferos, propondo um novo subgrupo taxonômico para os primeiros. 
Os Dinoceratas eram formas arcaicas de ungulados, que podiam ser relacionados aos mamíferos primitivos surgidos no Permiano? (cf. Marsh, 1886, p. 173, 177-9). A reconstrução da árvore da vida dos mamíferos estendia-se agora até um período geológico ainda mais antigo do que o Cenozóico, quando ocorreu sua grande diversificação e irradiação. A partir de então, esse grupo contava com uma das sequências evolutivas mais completas, que além de incluir diversos elos transacionais, também abrangia um enorme período de tempo, permitindo vislumbrar um recuo temporal necessário para a ocorrência dos processos de diversificação e irradiação.

Nesse momento, a elaboração de sequências evolutivas mais completas foi fundamental para a manutenção da paleontologia como uma área científica provedora de um importante suporte ao evolucionismo. Com o desenvolvimento da prática experimental na biologia no final do século XIX, áreas como a genética e a morfologia, por exemplo, passaram a produzir dados que podiam contribuir na elucidação dos processos evolutivos. A paleontologia permaneceu produzindo dados utilizáveis na elaboração das sequências evolutivas, mas nem sempre era possível completá-las, porque era, e ainda é, uma área científica dependente da descoberta de fósseis. As falhas no registro fossilífero não permitiam a completude de algumas sequências, deixando espaço para que os dados produzidos pela morfologia e embriologia as provessem. Dessa maneira, os morfologistas e embriologistas evolucionários podiam invocar uma hipotética forma ancestral ou intermediária, que relacionasse os componentes das sequências. Para elaborar essa forma hipotética, apoiavam-se em dados obtidos por meio da observação e da experimentação, que podiam revelar homologias entre organismos viventes e fósseis conhecidos. Essas homologias, por sua vez, possibilitavam uma compreensão satisfatória da morfologia da forma hipotética, permitindo o estabelecimento de relações filogenéticas entre ela e os componentes da sequência evolutiva proposta (cf. Bowler, 1996, p. 60, 314).

Entretanto, para elaborar tais sequências hipotéticas, fazia-se útil elucidar o padrão de evolução ao qual estava submetido o grupo taxonômico em questão. Nessa busca, vários evolucionistas passaram a defender que a evolução podia ocorrer de diversas maneiras, as quais podiam ser vistas como padrões evolutivos. Assim, propuseram, por exemplo, que ela pudesse ocorrer de maneira paralela, entre organismos ou grupos taxonômicos, que desenvolviam estruturas similares independentemente de compartilharem o mesmo ancestral comum, ou ainda, de maneira convergente, que ocorria quando duas formas originalmente diferentes passavam a ocupar um mesmo ambiente, adquirindo, assim, caracteres similares (cf. Bowler, 1996, p. 69). 
Mas os padrões evolutivos propostos geravam discussão entre vários evolucionistas e resultavam na elaboração de diferentes sequências evolutivas para um mesmo grupo taxonômico, contribuindo, assim, para o seu descrédito (cf. Scott, 1913, p. 649-5o; Déperet, 1945 , p. $107^{-15}$ ). Essa situação foi analisada pelo zoólogo e geneticista estadunidense Thomas Henry Morgan (1866-1945), em sua crítica à teoria da evolução, na qual afirmou que o estabelecimento desses padrões e das leis evolutivas dependia do conhecimento do fenômeno da hereditariedade. Este era um componente fundamental do processo evolutivo e, segundo Morgan, poderia ser compreendido somente por meio dos dados produzidos pela genética (cf. Morgan, 1916, p. 24-7).

Essa ciência, assim como outras áreas da biologia experimental, estava recebendo grande aceitação dos conhecimentos produzidos, em razão da mais pronta verificabilidade de suas hipóteses, em relação, por exemplo, à paleontologia. Algumas delas estavam voltadas à elucidação de vários processos biológicos, e objetivavam lançar luz sobre questões evolutivas dos grupos taxonômicos, como o desenvolvimento, a hereditariedade etc. (cf. Rainger, 1991, p. 18-21; 1992, p. 29-32). Tal aceitabilidade promoveu um grande desenvolvimento dessas ciências em um momento no qual centros de pesquisas estavam sendo criados em todo o mundo e, especialmente, em algumas instituições dos Estados Unidos da América.

\section{A ideia de PROgResso NA PALEONTOlOGIA AMERICANA}

A paleontologia nesse país já havia contribuído imensamente com inúmeras descobertas de fósseis, que completavam várias sequências evolutivas, desde os trabalhos de Richard Harlan (1796-1843), James E. Dekay (1792-1851) e Joseph Leidy (1823-1891) (cf. Rainger, 1992, p. 2-7). Embora os trabalhos de Harlan e Dekay tenham colocado os paleontólogos europeus a par das pesquisas paleontológicas realizadas em solo norte-americano, foram os trabalhos de Leidy que resultaram em uma contribuição direta ao evolucionismo.

Ele iniciou sua carreira cumprindo os objetivos cognitivos do programa de pesquisa cuvieriano para a paleontologia, determinando taxonomicamente inúmeros fósseis e aumentando, assim, o conhecimento das formas de organização corporal existentes na natureza. Nesse processo, Leidy descreveu vários animais extintos, que seriam utilizados, posteriormente, como formas transicionais nas sequências filogenéticas que os evolucionistas passaram a elaborar. Entretanto, até o momento da publicação da teoria de Darwin, Leidy ainda defendia que as plantas e os animais deveriam ser definidos como "formas orgânicas imutáveis, das quais distintas características devem sempre ser reconhecidas por um estudo de sua história" (cf. Leidy, 1853, p. 9; 
Rainger, 1992, p. $\left.7^{-10}\right)$. Esse posicionamento seria totalmente modificado em seus trabalhos posteriores a 1859, quando passou a procurar por formas intermediárias, que pudessem servir como "notáveis exemplos da teoria da seleção natural do eminente filósofo Darwin" (Leidy, 1869, p. 118; cf. Academy, 1870, p. 72-3; 1873; Osborn, 1913, p. 350-70; Rainger, 1992).

Leidy, que segundo o presidente do American Museum of Natural History (Museu Americano de História Natural), Henry Fairfield Osborn (1857-1935), era o "sucessor natural de Cuvier", havia mudado sua orientação teórica, passando a trabalhar na busca por evidências da evolução. Como o próprio Darwin disse em carta a Leidy, seus trabalhos exibiam "fatos impressionantes, que davam suporte à doutrina da seleção" (Darwin, 1861; Osborn, 1929, p. 169). Esse suporte se ampliava com as descobertas promovidas por trabalhos de paleontólogos compatriotas, como, por exemplo, Marsh.

Concomitantemente aos trabalhos deste último paleontólogo, Edward Cope (1840-1897) também estava realizando uma grande quantidade de descobertas fossilíferas em solo norte-americano, que rivalizavam com as de Marsh. Chegando às raias da competição com Marsh, ele escavou e descreveu uma enorme quantidade de fósseis, que lhe permitiram teorizar sobre vários assuntos, entre eles, o mecanismo orientador do processo evolutivo.

Cope, que fora aluno de Leidy, primeiramente procurou por fósseis que produzissem dados sobre a trajetória histórica da vida. Defensor do evolucionismo, entendia que a seleção natural poderia atuar no nível das espécies, mas não em níveis mais elevados taxonomicamente, como os gêneros (cf. Cope, 1868, p. 242-5; 1887, p. 3-4). Para este nível, existiriam outros mecanismos, que não deixavam à mercê do acaso as variações que produziam as inovações evolutivas, porque elas deveriam surgir pela mediação dos hábitos dos animais ou de tendências internas programadas (ortogênese) (cf. Cope, 1868, p. 269; 1887, p. viii-ix; 1904, p. 1-15; Bowler, 1983, p. 160-8; 1996, p. $65^{-}$) ). Tais proposições mostravam a influência que as antigas ideias evolucionárias de Lamarck passaram a ter após a aceitação do evolucionismo, tornando-se nos Estados Unidos, por meio de Cope e outros, uma forte corrente de pensamento. Conforme Peter Bowler (1996, p. 66), nesse momento, o importante fator evolutivo representado pela variação era compreendido pelos defensores de teorias, tais como a neolamarckista e a ortogenética, como um fator que respeitava tendências programadas, fossem elas internas ao organismo, ou produzidas pelo hábito, ou seja, de forma não aleatória, como proposto na teoria da seleção natural.

Essas teorias evolutivas serviram como instrumentos do questionamento à teoria da seleção natural durante as décadas que se seguiram à publicação do livro Origem das espécies (cf. Bowler, 1983, p. 218; 1996, p. 66). Durante esse período, que historiadores da ciência denominam "eclipse do darwinismo", utilizando o termo cunhado 
por Julian Huxley (1887-1975) (cf. Bowler, 1983, p. 5; Huxley, J., 2010 [1942], p. 22-8), os fósseis foram intensamente utilizados como fonte de dados para corroborar ou derrubar hipóteses sobre o mecanismo operante durante o processo evolutivo. Tais hipóteses foram produzidas durante essa disputa que se seguiu, na qual as teorias evolutivas propostas procuravam alcançar aceitação entre a comunidade científica.

Neolamarckistas como Cope defendiam que as inovações evolutivas deveriam surgir pela mediação dos hábitos dos animais, e eram herdadas pelos descendentes, resultando, ao longo do tempo, em um acúmulo de modificações que davam origem a novos táxons (cf. Cope, 1904, [1896], p. 518-28). Os ortogeneticistas, por sua vez, defendiam que existiam tendências internas programadas que guiavam o curso da evolução e que as sequências evolutivas baseadas nos fósseis podiam evidenciar o resultado evolutivo da ação dessas forças (cf. Eimer, 1898, p. 19; Bowler, 1996, p. 64-6; Mayr, $199^{8}$, p. $5^{8} 5^{-92}$ ). Existiam ainda os defensores da teoria da recapitulação, que consideravam haver na evolução de um organismo uma repetição de sua ontogenia e de seu ciclo de vida, capaz, inclusive, de explicar sua extinção (cf. Hyatt, 1897, p. 161, 167).

Eram teorias proponentes de mecanismos alternativos à seleção natural, que procuravam evitar o elemento aleatório proposto pela teoria de Darwin. Ao evitá-lo, seus proponentes facilitavam a defesa da existência, no processo evolutivo, de uma tendência ao incremento progressivo de complexidade na organização corporal. Tal facilidade decorria da eliminação desse elemento aleatório que se mostrava difícil de ser compatibilizado com a ideia de um processo com qualquer tipo de direcionamento.

Entretanto, apesar do fator aleatório variacional da teoria da seleção natural, Marsh, um de seus defensores, propunha que pudesse haver um aumento dessa complexidade, mesmo que o mecanismo proposto por Darwin estivesse atuando. Propunha, ainda, que esse aumento fosse uma consequência de tal atuação. Como exemplo, ele utilizou o crescimento cerebral dos mamíferos ao longo do Terciário, como fator que lhes permitiu suceder os dinossauros na luta pela existência, porque estes últimos mantiveram seus cérebros diminutos e, consequentemente, menos aptos para desempenhar as funções envolvidas nessa luta. O crescimento cerebral mamaliano, que podia ser considerado um aumento de complexidade de organização corporal, era uma consequência da atuação aleatória de elementos variacionais envolvidos no processo evolutivo, orientado pela seleção natural (cf. Marsh, 1877, p. 55).

Mesmo com as proposições de mecanismos alternativos à seleção natural, ou da existência de um elemento progressivo atuando na evolução, muitos paleontólogos seguiam na elaboração de sequências evolutivas que, à medida que se tornavam mais completas, criavam condições para a formulação de mais hipóteses sobre a origem dos grandes grupos taxonômicos. Marsh e Huxley já haviam defendido a origem americana dos 
cavalos, mas sem avançar muito sobre a origem dos mamíferos. Tal avanço ocorreu com o aporte de inúmeros fósseis escavados na América do Sul.

Com o avanço que a paleontologia fez durante o século xıx e início do xx, mesmo que o desenvolvimento da biologia experimental, de certo modo, possa tê-lo obscurecido, vários centros de estudo formaram-se, resultando em uma irradiação do conhecimento produzido nessa área científica. Foi o que ocorreu nos Estados Unidos da América, com a criação de museus e universidades como, por exemplo, o Museu Americano de História Natural, o National Museum of Natural History (Museu Nacional de História Natural) e a Universidade de Princeton, que se somavam a outros centros existentes em universidades e academias científicas estabelecidas anteriormente.

Trabalhando à frente do Museu Americano de História Natural, Henry Fairfield Osborn tratou de ampliar a coleção desse museu, com o objetivo de realizar vários estudos sobre a paleontologia dos vertebrados. Para um desses trabalhos, esforçou-se em apoiar a expedição à Patagônia promovida pela Universidade de Princeton, enviando para lá o paleontólogo Barnum Brown (1873-1963), pertencente aos quadros daquele museu, com o objetivo de escavar fósseis capazes de lançar luz na polêmica iniciada com a proposição de Florentino Ameghino (1854-1911) sobre a origem sul-americana dos mamíferos placentários (cf. Wortman, 1896, p. 262; Brown, 1903, p. 4533 Simpson, 1984a, p. 118-21; Rainger, 1991, p. 93).

A paleontologia na Argentina, que já contava com o apoio de algumas instituições de fomento ao estudo da história natural como, por exemplo, o Museo Nacional de Paraná, recebeu um grande impulso com a criação do Museo Nacional de Buenos Aires e do Museo de La Plata, além de universidades, academias e associações científicas (cf. Podgorny \& Lopes, 2008, p. 33-4, 52-4, 174-8). Hermann Burmeister (1807-1892), à frente do Museo Nacional de Buenos Aires, fez grandes avanços com os estudos sobre os fósseis argentinos que resultaram na formulação de hipóteses sobre a extinção e evolução de vários organismos. De uma maneira cuvieriana, ele defendeu que os mamíferos sul-americanos do Terciário tinham sido extintos por um cataclismo geológico, uma inundação, a qual também formara o estrato em que eram escavados (cf. Burmeister, 1864, p. 29). Para Burmeister, esses e outros organismos poderiam variar, ao longo do tempo, mas não poderiam extrapolar determinados limites, que os definiam como tipos. Esses limites impediam que existissem transformações capazes de levar ao surgimento de novas espécies ou grupos taxonômicos, ou seja, à evolução (cf. Burmeister, 1879, p. 11-3).

Opondo-se às ideias fixistas de Burmeister, Florentino Ameghino assumiu em 1902 a diretoria do Museo Nacional de Buenos Aires e pôde contar com mais uma coleção já bem formada de mamíferos fósseis, a qual utilizou na defesa de sua hipótese sobre a 
origem desse grupo taxonômico. Para ele, a América do Sul, mais precisamente a $\mathrm{Pa}-$ tagônia, região na qual foi escavada grande parte dos fósseis que estudou, era o centro de origem e irradiação dos mamíferos (cf. Ameghino, 1897). Levando em consideração as questões da anatomia comparada, da embriologia e o resultado da atuação de processos evolutivos, Ameghino defendeu que era possível elaborar filogenias de grupos taxonômicos, estabelecendo relações matemáticas entre caracteres quantificáveis, como, por exemplo, os dentes, e sua distribuição anatômica (cf. Ameghino, 1915, p. 68, 321-45).

Aplicando tais métodos nos fósseis de mamíferos patagônicos, ele descreveu e classificou uma grande quantidade deles, que, segundo as posições estratigráficas utilizadas, indicavam uma antiguidade maior do que a dos mamíferos placentários fósseis encontrados na Europa, inclusive para o homem (cf. Ameghino, 1917, p. 174). Evidentemente essa hipótese recebeu vários questionamentos provenientes da Europa e também da América do Norte. Como resultado dessa situação, expedições como a da Universidade de Princeton partiram para a Patagônia, tendo como um de seus objetivos a verificação dos dados nos quais Ameghino se apoiava para defender sua hipótese, principalmente os estratigráficos. O paleontólogo argentino estava sendo intensamente criticado pelos critérios utilizados para estabelecer as sequências estratigráficas, que datavam os fósseis de mamíferos placentários patagônicos como cretáceos, ${ }^{\mathbf{8}}$ ou seja, muito mais antigos do que os fósseis europeus (cf. Scott, 1903, p. viI).

Apesar de Barnum Brown ter acompanhado aquela expedição e descrito vários fósseis de mamíferos do Terciário da Patagônia, foi por meio de estudos realizados por vários paleontólogos de diversas instituições norte-americanas, inglesas, francesas e brasileiras, que críticos de Ameghino, como John Bell Hatcher (1861-1904), à frente da expedição da Universidade de Princeton, e Osborn, obtiveram elementos para refutar a hipótese da origem sul-americana dos mamíferos, baseada em uma maior antiguidade destes em relação aos europeus (cf. Lydekker, 1896, p. 21; Gaudry, 1907; Ortmann, 1911, p. 665). Tais estudos apuraram as posições estratigráficas dos mamíferos fósseis patagônicos, indicando que eram mais recentes do que Ameghino defendia, porque abaixo dos estratos geológicos em que se encontravam foram escavados fósseis de invertebrados assemelhados à fauna cenozóica do Velho Mundo e da Oceania (cf. Hatcher, 1902, p. 130-1; Ihering, 1902, p. 133; Osborn, 1910, p. 39-50).

Estudos como esses não apenas contribuíram para o esclarecimento da questão da antiguidade dos mamíferos placentários, mas também levantaram questões sobre a possível existência, no passado, de conexões entre as massas continentais da América do Sul e da Antártica (cf. Osborn, 1900, p. 565; Ortmann, 1901a, p. 139-42). Segundo 
Ortmann (1901a, p. 311; 1901b, p. 139), tal questão já havia sido tratada pelo botânico Joseph Hooker (1817-1911), quando, em 1847, notou a grande semelhança existente entre as floras da região austral desses continentes (cf. Hooker, 1847, p. 211) e, seis anos mais tarde, quando propôs que estiveram conectados (cf. Hooker, 1853, p. xxiii). Em 1859, já influenciado pela publicação do Origem das espécies, Hooker avançou nessa proposição, explicando que a distribuição das espécies atuais remanescentes da flora austral era um resultado de sua luta pela sobrevivência, principalmente em relação às mudanças das condições climáticas da Terra que ocorreram ao longo dos "períodos geológicos recentes" (cf. Hooker, 1859, p. xvii-xviii, civ).

Osborn também apontou Hooker como o precursor da teoria da conexão entre as massas de terras austrais, citando, além de seus trabalhos, os estudos de Ameghino, Hatcher e Ortmann (cf. Osborn, 1910, p. 75-6). Huxley também foi citado como defensor dessa teoria, propondo que essa grande massa de terra existiu durante o Mesozóico, explicando, assim, não só a distribuição transcontinental dos fósseis dos mamíferos, como também dos grandes répteis (cf. Osborn, 1910, p. 75).

\section{A IdEIA DE PROGReSSO NA EVOLUÇÃo E OS DINOSSAURos: GRISE E EXTINÇÃo}

Entre os séculos XIX e Xx, uma grande quantidade de fósseis de dinossauros continuava sendo escavada na América do Norte e Ásia, reforçando assim a hipótese de que as massas continentais estiveram unidas no passado, porque provinham de espécies relacionáveis taxonomicamente. Mas, diferentemente dos mamíferos, esses fósseis passaram a chamar a atenção também para a forma como ocorreu o desaparecimento de um grupo taxonômico tão numeroso.

Quando John Phillips (1800-1874) propôs os termos Paleozóico, Mesozóico e Cenozóico para denominar as eras geológicas, ele tinha em mente que os limites entre elas deveriam ser estabelecidos com base em eventos de grande escala, ocorridos durante a história da vida sobre a Terra (cf. Phillips, 1841, p. 159-60). Mesmo sem discutir a extinção dos dinossauros, o limite entre a era Mesozóica e a Cenozóica, ${ }^{9}$ que sua proposição estabelecia, coincidia com o evento da extinção dos grandes répteis mesozóicos.

O acúmulo de dados sobre esse grupo taxonômico, resultante do grande número de descobertas ocorridas ao longo do século xIx, tornou possível a constatação do seu súbito desparecimento no registro fóssil. Darwin explicava essa subtaneidade invocando a imperfeição do registro fossilífero, resultante da raridade da ocorrência dos processos de fossilização, de dinâmicas geológicas, dos processos de migração de gru-

9 Compreendidas, respectivamente, entre 24,8 e 65 milhões de anos atrás e entre 65 milhões de anos e a atualidade. 
pos taxonômicos etc. (cf. Darwin, 1859, p. 279-345). Ele reservou dois capítulos de Origem das espécies para tratar da "mais séria e evidente objeção a sua teoria”, ou seja, a escassez de formas transicionais no registro fóssil (Darwin, 1859, p. 280).

A sequência evolutiva relacionando o Compsognathus e o Archaeopterix indicava a existência de uma das raras cadeias transicionais citadas por Darwin, explicando o surgimento das aves, mas não a extinção súbita dos dinossauros. Por sua vez, os defensores da seleção natural argumentavam que a imperfeição do registro fóssil causava a impressão de um rápido desaparecimento desse grupo taxonômico, mas que, na verdade, ele havia sucumbido gradualmente, ao enfrentar na luta pela sobrevivência novas condições ambientais, provocadas, por exemplo, pelas modificações climáticas iniciadas no final do Cretáceo (cf. Zittel, 1900, p.13-5; Matthew, 1915, p.176-9).

Por sua vez, vários defensores das teorias da ortogênese e da recapitulação não consideravam que a subtaneidade da extinção dos dinossauros fosse apenas uma impressão. Para alguns desses ortogeneticistas, a existência de uma tendência ao aumento de complexidade na organização corporal, orientando os processos evolutivos, podia explicar a extinção, uma vez que tal aumento poderia levar os organismos a desenvolverem, em um curto período de tempo, estruturas morfológicas tão complexas, grandes e pesadas que os inabilitariam para lutar por sua sobrevivência. Argumentavam que poderia ter ocorrido com os dinossauros algo similar ao que ocorrera com os tigres dente-de-sabre, quando um extremado aumento de seus dentes passou a dificultar sua mordedura, de tal forma que diminuiu sua habilidade de caça e, consequentemente, suas chances na luta pela sobrevivência (cf. Schindelwolf, 1993, p. 279-86).

Os defensores da teoria da recapitulação afirmavam que os grupos taxonômicos tinham ciclos de existência comparáveis aos ciclos de vida dos organismos que os compunham, cumprindo durante seu processo evolutivo os estágios de nascimento, infância, maturidade e senilidade, ou seja, surgimento no registro fóssil, rápido desenvolvimento e irradiação, estabilidade e extinção (cf. Hyatt, 1897, p. 161; Cope, 1904, p. 145, 522). Essas sequências podiam ser consideradas como resultado de uma tendência ao aumento de complexidade das formas de organização corporal, ocorrente durante o processo evolutivo, a qual conduzia a uma especialização de tal nível que podia ser deletéria para o próprio organismo que estivesse evoluindo. Isso ocorrera com os tigres dente-de-sabre e poderia ter ocorrido, de alguma maneira, com os dinossauros.

Com essas explicações, os ortogeneticistas e recapitulacionistas procuravam explicar a subtaneidade da extinção dos dinossauros, sem invocar o fator gradualista que a teoria da seleção natural requeria. Entretanto, defender que fora uma tendência ao aumento da complexidade das formas de organização corporal, ocorrente no processo evolutivo, o fator determinante da extinção de um grupo taxonômico inteiro, tornava- 
se uma tarefa cada vez mais difícil. Como decorrência dessa e de outras dificuldades, paleontólogos como Richard Lull (1867-1957), do Peabody Museum of Natural History (Museu Peabody de História Natural), passaram a propor hipóteses que vinculavam o evento da extinção em massa dos dinossauros com transformações ambientais decorrentes da ação de forças geológicas. Por exemplo, ele propôs que no final do Cretáceo houve uma elevação de massas continentais, que teria drenado o suposto ambiente semiaquático habitado pelos dinossauros, impossibilitando sua sobrevivência (cf. Lull, 1927, p. 531, 690). O debate sobre as hipóteses de extinção por fatores geológicos, como a de Lull, avançou de tal maneira que resultou na proposição de Joseph Le Conte (18231901) sobre o desenvolvimento de novas formas de organização corporal, durante o processo evolutivo, em contínua relação com as transformações ambientais que a Terra sofrera ao longo de sua história (cf. Le Conte, 1897, p. 53-66).

Lull também apoiava essa hipótese, mas propondo que a evolução ocorria na forma de "pulsos", ou seja, com a ocorrência de eventos súbitos e sucessivos de transformação das formas de organização corporal, que eram induzidos por rápidas transformações do ambiente (Lull, 1927, p. 687-91). Estendendo essa hipótese, o paleontólogo do Walker Museum of Paleontology (Museu Walker de Paleontologia) Alfred Romer (18941973) propôs que a formação das Montanhas Rochosas, ao final do Cretáceo, tivera imensos reflexos nas condições climáticas responsáveis pela extinção dos dinossauros (cf. Romer, 1960, p. 89).

Com essas hipóteses, a ação de forças do ambiente físico, no caso as forças geológicas, passavam a integrar, com muito mais intensidade, as explicações sobre o processo evolutivo. Além disso, a aleatoriedade dos processos geológicos facilitava a aceitação de componentes estocásticos atuando no processo evolutivo, como os que estavam implícitos na teoria da seleção natural. Essa aceitação foi muito importante para o arrefecimento da defesa da existência de uma tendência ao aumento progressivo da complexidade das formas orgânicas, ao longo do processo evolutivo.

Esse abrandamento facilitou a aceitação da hipótese defendida por paleontólogos que consideravam a possibilidade de que a evolução pudesse ocorrer de forma paralela entre grupos taxonômicos relacionados. Demonstravam assim algumas sequências evolutivas, como a dos equídeos, que além da linhagem estabelecida entre o Paleotherium e a forma moderna, o Eqqus, exibiam também, como ramos de uma árvore, linhagens paralelas de perissodátilos, que se extinguiram durante o processo. Esse paralelismo podia indicar que enquanto uma linhagem estava evoluindo progressivamente para formas de organização corporal cada vez mais complexas, outras estavam mantendose sem modificações, ou mesmo diminuindo sua complexidade organizacional (cf. Huxley,1899, p. 353-64; Scott, 1891, p.72; Mason, 1928, p. vII). 
Essas discussões sobre os processos, mecanismos e padrões evolutivos, provocadas pelos dados provenientes dos fósseis, arrastaram-se até praticamente a década de 194,0, momento no qual os paleontólogos formularam hipóteses sobre o mecanismo da seleção que resultaram em uma "síntese moderna", integrando a teoria da seleção natural e os fundamentos da genética de populações (cf. Simpson, 1949, p. 275-80; Bowler, 1996, p. 351-2; Huxley, J., 2010 [1942], p. 22-8).

A genética, uma das áreas mais promissoras da biologia experimental naquele momento, já havia proposto teorias que rompiam com a ideia de progressividade atuando na evolução (cf. De Vries, 1905, p. 16; Morgan, 1916, p. 187-8; Simpson, 1949, p. 275). A aplicação da matemática na análise genética da população permitiu a formulação de modelos teóricos testáveis, nos quais a ação da seleção natural e seu fator aleatório antiprogressionista tinham um papel fundamental (cf. Bowler, 1983, p. 216).

No campo da paleontologia, George Simpson (1902-1984), trabalhando no $\mathrm{Mu}$ seu Americano de História Natural, começou a aplicar análises estatísticas de populações de organismos extintos para determinar os limites interespecíficos entre as espécies de organismos fósseis. Por meio desses limites, Simpson pôde estabelecer taxas de evolução que indicavam padrões do processo evolutivo variando ao longo do tempo, ou seja, acelerando (evolução taquitélica) ou retardando (evolução braditélica) o ritmo deste processo. Essa variação podia explicar a "mais séria e evidente objeção" à teoria de Darwin: a escassez de formas transicionais no registro fóssil (cf. Eldredge, 1984 [1944], p. XI). Durante os períodos de aceleração, havia uma pequena probabilidade de fossilização de um número representativo de espécimes, ao passo que essa quantidade aumentava nos períodos de retardamento, criando assim uma falsa impressão de que o registro fóssil era falho, principalmente para os defensores da existência de um fator de aumento progressivo de complexidade atuando no processo evolutivo (cf. Simpson, 1984, b [1944], p. 105-15).

Tais conclusões contribuíram para enfraquecer a defesa da existência de uma tendência ao aumento de complexidade ditando a evolução, que poucos paleontólogos ainda faziam (cf. Bowler, 1996, p. 351-2). Havia agora mais um elemento aleatório, a aceleração e o retardamento das taxas evolutivas, que se integrava às explicações sobre o processo evolutivo, dificultando ainda mais a defesa da ideia de progresso na evolução. Com a "síntese moderna", como a denominou Julian Huxley, o próprio sentido de progresso na biologia seria alterado para indicar, a partir de então, um aumento da capacidade adaptativa externa e interna dos organismos (cf. Huxley, J., 2010 [1942], p. 22-8; Caponi, 2011, p. 128). A natureza vivente e os fósseis podiam evidenciar que seres menos complexos, em relação a sua organização corporal, se bem adaptados, podiam ser considerados mais avançados do que os organismos mais complexos (cf. Huxley, J., 1928, p. 332-5). Essa foi mais uma inversão que as teorias de Darwin provo- 
caram dentro do campo da história natural, assim como aquela promovida pela introdução da ideia de luta pela existência, quando os seres vivos passaram a ser percebidos não mais como meros ocupantes de um lugar assegurado a eles na natureza, mas como competidores que visam conquistá-lo (cf. Caponi, 2008, p. 128-9).

\section{Considerações Finais}

Com a aceitação dos métodos e do programa de pesquisa de Georges Cuvier para o estudo dos fósseis, houve a percepção da ocorrência de uma sucessão biótica ao longo da história da Terra, que podia ser interpretada como um indício da existência de uma tendência ao aumento progressivo da complexidade das formas de organização corporal dos organismos que se sucediam. Nesse momento, vários defensores de teorias transformistas consideravam que esse progressivo aumento de complexidade cumpria uma escala de seres conduzindo à manifestação das formas ao longo do tempo na direção de um ponto máximo, onde estava o homem.

Com a aceitação do evolucionismo, essa discussão tornou-se mais complexa, uma vez que as teorias evolutivas foram utilizadas tanto como fator de defesa, como de refutação, para a ocorrência de uma tendência dos organismos a um progressivo aumento de complexidade em sua organização corporal, durante o processo evolutivo.

Defensores da teoria da seleção natural, como Thomas Huxley, que utilizaram sequências filéticas para defender a ideia de evolução, não aceitavam que nelas existisse algum indício da existência de alguma tendência orientando o processo evolutivo. Para eles, a variação, um importante componente da teoria da seleção natural, ocorria de forma aleatória, não obedecendo nenhuma tendência.

Entretanto, em um momento em que a teoria evolutiva proposta por Darwin sofria grandes críticas, outras teorias evolutivas surgiram, sendo que, em algumas delas, a ideia de progresso constava como um elemento presente no processo evolutivo. Seus defensores também utilizavam as sequências evolutivas, porém com o propósito de indicar a ocorrência de uma tendência ao aumento da complexidade orgânica.

De certa forma, os trabalhos de Marsh, um defensor da seleção natural, auxiliaram na superação dessa dificuldade, pois podiam ser utilizados por naturalistas que defendiam que a atuação do mecanismo proposto por Darwin poderia resultar em tal incremento, como no caso do crescimento cerebral dos mamíferos ao longo do Terciário. Esse crescimento podia ser interpretado como um incremento de complexidade funcional orientado pela seleção natural, uma vez que houve uma pressão seletiva dirigindo o processo naquele sentido. 
Por outro lado, os defensores da existência de uma tendência ao aumento da complexidade orgânica no processo evolutivo deparavam-se com algumas dificuldades, como, por exemplo, a extinção de grupos inteiros que haviam adquirido uma incessante complexidade, que os inviabilizou na luta pela sobrevivência. Além disso, essa argumentação também se enfraquecia perante a constatação de que poderiam existir sequências evolutivas paralelas na evolução de um único grupo taxonômico. Mediante a comparação entre essas sequências era possível defender que algumas formas de organização corporal, relacionadas filogeneticamente, aumentavam progressivamente sua complexidade, enquanto outras diminuíam. Segundo os defensores da teoria de Darwin, isso deveria ocorrer de forma aleatória, já que havia um elemento estocástico na explicação variacional do processo evolutivo operado pela seleção natural.

Tal aleatoriedade foi reforçada por vários estudos genéticos, e também pelos trabalhos de George Simpson, que constatou, por meio de análises estatísticas de populações de organismos extintos, que os padrões evolutivos variavam ao longo do tempo, não apresentando nenhuma progressão quanto a sua complexidade funcional. Suas ideias sobre a evolução somaram-se às de outros evolucionistas, culminando na elaboração da "síntese evolutiva moderna", que integrava a teoria de Darwin com conhecimentos e teorias provenientes de várias áreas da biologia, como a genética, a morfologia, a paleontologia etc. Sendo a seleção natural o mecanismo operante do paradigma da biologia moderna, houve, a partir desse momento, pouco espaço para a defesa de uma tendência ao aumento progressivo da complexidade corporal, ocorrendo no processo evolutivo.

Percebendo essa situação, e a importância que a ideia de progresso teve na história do evolucionismo, Julian Huxley propôs que a capacidade adaptativa deveria ser o critério para o estabelecimento de um padrão de progresso evolutivo. O estado de progresso atingido por um grupo taxonômico deveria ser analisado em função de sua adaptação às condições de vida que enfrentava e não mais em razão de sua complexidade funcional. E, assim, o sentido da ideia de progresso foi profundamente alterado no âmbito da biologia.

Era uma nova forma de apresentar uma questão, que se fez presente durante todo o desenvolvimento da paleontologia, assim como do próprio pensamento biológico. Tendo sido submetido às modificações requeridas para integrar-se às explicações das teorias evolutivas que tais naturalistas defendiam, o sentido da ideia de progresso foi sendo alterado ao longo do tempo.

Independentemente das formas com as quais os evolucionistas abordavam a maneira como a progressividade era manifestada, todas elas não permitiam uma acomodação do elemento estocástico constante na teoria da seleção natural. Por tal razão, a ideia de um aumento de complexidade, ocorrendo durante o processo evolutivo e sendo direcionada por algum fator, perdeu força quando da aceitação de tal teoria. 
Entretanto, com essa aceitação, tal ideia foi transferida da exclusiva área funcional interna do organismo para a externa, onde, em sua luta pela sobrevivência, ele deve adaptar-se ao meio externo, respeitando os limites da funcionalidade interna. Tais limites foram discutidos por Cuvier, em estudos em que constatou o fenômeno da sucessão biótica e, mesmo sem defender a ideia da existência na natureza de uma tendência ao aumento da complexidade funcional, possibilitou que esta última pudesse apoiarse em evidências de que a história da vida seguiu algum tipo de padrão progressivo.

A partir de então, a ideia de progresso na natureza pôde ser defendida pelos naturalistas, evolucionistas ou não, sem que houvesse a necessidade de invocar qualquer elemento ideal, como a escala de seres. Essa situação pode ter dificultado a aceitação da teoria da seleção natural, que requeria um elemento de aleatoriedade variacional, praticamente inviabilizador da defesa da existência de qualquer tendência atuando na evolução. Somente após a elaboração da "síntese evolutiva moderna", e a consequente aceitação do mecanismo evolutivo proposto por Darwin, é que a ideia da existência de uma tendência natural ao progresso dos seres vivos foi modificada de tal forma que rompeu com o velho progressionismo. Este, que estava baseado na ideia escalar, onde o homem ocupava o ápice, praticamente coincidia com a ideia de progresso social, defendida naqueles tempos em que as ideias positivistas estavam sendo intensamente debatidas (cf. Bury, 1920, p. 334-349).

Tal coincidência pode ter contribuído para a rápida aceitação da teoria evolutiva de Darwin, baseada na unidade de tipo, ao mesmo tempo em que pode ter dificultado a aceitação da teoria da seleção natural, que não apenas havia retirado o homem do seu posto apical, mas que o colocara em seu real lugar na natureza. Entretanto, passadas algumas décadas, tal dificuldade seria superada pela "síntese moderna". Daí em diante, o progresso, como forma de avanço em direção às conquistas da condição humana, não faria mais parte das explicações sobre como ocorreu a história da vida na Terra. Tal história, assim como a evolução, tinha componentes contingenciais que não cumpriam nenhuma tendência, interna ou externa, aos organismos.@

Felipe FARIA

Pós-doutorando do Programa de Pós-Graduação em Filosofia, Grupo Fritz Muller-Desterro de Estudos em Filosofia e História da Biologia, Universidade Federal de Santa Catarina. Grupo de Pesquisa de Paleoinvertebrados e Icnofósseis do Brasil, Universidade Federal do Rio de Janeiro, Brasil. ffelipe.faria@pq.cnpq.br 


\begin{abstract}
The idea that there is a tendency of organisms towards a progressive increase of complexity of bodily organization was already present before the rise of evolutionism. With the acceptance of evolutionary theories, many naturalists, especially those working with fossils, embraced the occurrence of such a tendency in the evolutionary process. This new way of approaching the idea of progress in nature received various interpretations up to the time of the emergence of the modern evolutionary synthesis, which left little room for the existence of another guiding element of evolution different from the one proposed by Darwin.
\end{abstract}

KEYwords $\bullet$ Progress. Complexity. Body organization. Evolution. Fossils.

\title{
REFERÊNGIAS BIBLIOGRÁFIGAS
}

Academy of natural sciences of Philadelphia. Proceedings of the Academy of Natural Sciences of Philadelphia, p. $72-4,1870$. Proceedings of the Academy of Natural Sciences of Philadelphia, p. 416-7, 1873.

Agassiz, E. Louis Agassiz: his life and correspondence. London: Macmilliam \& Company, 1885. v. 1.

Agassiz, L. Recherches sur les poisons fossils. Neuchatel: Imprimerie de Petipierre, 1833. v. 1.

. Principles of zoology: touching the structure, development, distribution and natural arrangement of the races of animals living and extinct. Boston: Gould \& Lyncoln, $185^{3}$. An essay on classification. London: Longman \& Company, 1859. An essay on classification. Cambridge: Harvard University Press, 1962 [1857].

Alberdi, M. et al. Anchitherium aurelianense (Mammalia Equidae) (Cuvier, 1825) dans l'Oléanien (Miocène) de France. Geodiversitas, 26, 1, p. 115-55, 2004.

Ameghino, F. South America as the source of the tertiary mammalia. Natural Science, 11, p. 256-64, 1897 . Filogenia. Buenos Aires: La Cultura Argentina, 1915.

Florentino Ameghino: Doctrinas y descubrimientos. Buenos Aires: La Cultura Argentina, 1917.

Bowler, P. Fossils and progress: paleontology and the idea of progressive evolution in the nineteenth century. Chicago: Science History Publications, 1976.

. The eclipse of darwinism: anti-darwinian evolution theories in the decades around 1900. Baltimore: Johns Hopkins University Press, 1983.

. Life's splendid drama. Chicago: Chicago University Press, 1996.

Brown, B. A new species of fossil edentate from the Santa Cruz formation of Patagonia. Bulletin of the American Museum of Natural History, 19, p. 453-57, 1903.

Burmeister, H. La paleontología actual en sus tendencias y resultados. Anales del Museo Público de Buenos Aires, 1, 1, p. 12-31, 1864 .

. Description physique de la République de Argentine, d'après des observations personelles et étrangères, animaux vertébrés. Buenos Aires: Paul-Émile Coni, 1879. t. 3.

BuRY, J. The idea of progress: an inquiry into its growth and origin. London: Macmillan \& Company, 1920.

CAponi, G. Los objetivos cognitivos de la paleontologia cuvieriana. Principia, 8, 2, p. 233-58, 2004 . Georges Cuvier: um fisiólogo de museo. México: Universidad Nacional Autónoma de México, 2008. . La segunda agenda darwiniana: contribución preliminar a uma historia del programa adaptacionista.

México, DF: Centro de Estudios Filosoficos y Sociales Vicente Lombardo Toledano, 2011.

Chambers, R. Vestiges of the natural history of creation. London: John Churchill, 1844. 
Chambers, R. Explanations: a sequel to "Vestiges of the natural history of creation", by the author of that work. Nova York: Wiley \& Putnan, $184,6$.

Conry, Y. L'introduction du darwinisme en France au XIX siècle. Paris: Vrin, 1974.

Cope, E. On the origin of genera. Proceedings of the Academy of Natural Sciences of Philadelphia, p. 24,2-3०5, 1868.

The origin of the fittest: essays on evolution. Nova York: Appleton \& Company, ${ }_{188} 7$.

Primary factors of organic evolution. Chicago: Open Court, 1904, [1896].

Guvier, G. Recherches sur les ossemens fossiles de quadrupèdes, ou l'on rétablit les caractères de plusier espèces d'animaux que les révolutions du Globe paroissent avoir détruite. Paris: Deterville, 1812a. t. 1.

Recherches sur les ossemens fossiles de quadrupèdes, ou l'on rétablit les caractères de plusier espèces d'animaux que les révolutions du Globe paroissent avoir détruite. Paris: Deterville, 1812b. t. 3.

. Discours sur les révolutions de la surface du Globe, et sur les chagements qu'elles ont produits dans le règne animal. Paris: Edmond D’Ocagne, 1830.

Darwin, C. Carta de Darwin a Lyell, o8/10/1845. Disponível em: <http://www.darwinproject.ac.uk/entry$15^{8} 7$ >. Acesso em: o / $/ 06 / 2011$.

. Carta de Darwin a Huxley, o2/o9/1854. Disponível em: <http://www.darwinproject.ac.uk/entry919>. Acesso em: o7/06/2011.

. On the origin of species. London: Murray, 1859.

. Carta de Darwin a Leidy, o4/o3/1861. Disponível em: <http://www.darwinproject.ac.uk/entry3०81>. Acesso em: ०8/०6/2011.

DePÉRET, C. Las transformaciones del reino animal. Buenos Aires: Impulso, 1945.

De VRIEs, H. Species and varieties: their origin by mutation. Chicago: Open Court, 1905.

EImer, T. On orthogenesis and the importance of natural selection in the species-formation. Chicago: Open Court, 1898.

Eldredge, N. Foreword. In: Simpson, G. Tempo and mode in evolution. New York: Columbia University Press, 1984, [1944]. p. XI.

Eronen, J. et al. The impact of regional climates on the evolution of mammals: a case study using fossil horses. Evolution, 64, 2, p. 398-4,08, 2009.

FAria, F. Georges Cuvier: do estudo dos fósseis à paleontologia. São Paulo: Associação Filosófica Scientiae Studia/Editora 34, 2012.

Foster, M. \& Lankester, R. (Ed.). The scientific memoirs of Thomas Henry Huxley. London: Macmillam \& Company, 1902. v. 4 .

GAUDRY, J. Animaux fossiles et géologie de l'attique, d'après les recherches faites em 1855-1856 et en 1860. Paris: F. Savi, 1862.

. Les enchainements du monde animal dans les temps géologiques: mamifères tertiaires. Paris: Hachette, 1878 .

. Essay de paléontologie philosophique. Paris: Masson, 1896.

Patagonia and Antarctica. Science, 26, p. 350-3, 1907.

Grant, R. Observations on the nature and importance of geology. The Edinburgh New Philosophical Journal (April...October), p. 293-302, 1826.

Hatcher, J. Origin of the oligocene and miocene deposits of the great plains. Proceedings of the American Philosophical Society, 16, 169, p. 113-31, 1902.

Ноокев, J. The botany of the Antarctic voyage, vol. I - Flora Antarctica, part II - Botany of Fuegia, the Falklands, Kerguelen's Land, etc. London: Reeve, 1847 .

. Introductory essay to the flora of New Zealand. London: Lovell Reeve, $185^{3}$.

. On the flora of Australia, its origin, affinities, and distribution. London: Lovell Reeve, 1859. 
Huxley, J. Progress shown in evolution. In: Mason, F. (Ed.). Creation by evolution: a consensus. New York: Macmillan \& Company, 1928. p. 327-39.

Evolution: the modern synthesis (the definitive edition). Cambridge: The MIT Pres, 2010 [1942].

HuxLEY, T. Evidence as to man's place in nature. New York: Appleton \& Company, 1863.

On the animals wich are most nearly intermediate between birds and reptiles. The Annals and Magazine of Natural History, 2, 4, p. 66-75, 1868.

. Lectures on evolution. In: CuAY, R. (Ed.). Collected essays by T. H. Huxley. London: Macmillan \& Company, 1893 [1876].v. 4, p. 46-138.

. Geological contemporaneity and persistent types of life. In: essays. New York: Appleton \& Company, 1896a [1862]. v. 8, p. 272-3०4.

. Paleontology and the doctrine of evolution. In: Discourses biological and geological essays. New York: Appleton \& Company, 1896b [1870].v. 8, p. 340-88.

. On our knowledge of the causes of the phenomena of organic nature. In: Darwiniana - collected essays. London: Macmilliam \& Company, 1899. v. 2, p. 3०3-475.

. On the application of the laws of evolution for the arrangement of the vertebrata and more particularly of the mammalian. In: Foster, M. \& Lankester, R. (Ed.). The scientific memoirs of Thomas Henry Huxley. London: Macmillam \& Company, 1902 [1880]. v. 4, p. 457-72.

Нуaтt, A. Cycle in the life of the individual (onthogeny) and in the evolution of its own group (phylogeny). Science, 5,109, p. 161-71, 1897 .

Inering, H. On the molluscan fauna of the Patagonian tertiary. Proceedings of the American Philosophical Society, 16, 169, p. 132- $7,1902$.

JAMEson, R. A system of mineralogy. Edimburgo: William Blackwood, 1808. v. 3.

Kovalevskr, W. On the osteology of the hypopotamidae, by Dr. Kowalevsky, communicated by Professor Huxley. Philosophical Transactions of the Royal Society of London, 163, p. 19-94, 1873.

Kunn, T. The structure of scientific revolutions. Chicago: University of Chicago Press, 1962.

LE ConTe, J. Evolution: its nature, its evidences, and its relation with religious thought. New York: Appleton \& Company, 1897 .

LEIDY, J. A flora and fauna within living animals. Washington: Smithsonian Institution, $185^{3}$.

. The extinct fauna of Dakota and Nebraska. Philadelphia: Academy of Natural Sciences, 1869.

Lovejoy, A. The great chain of being. Cambridge: Harvard University Press, 1964.

LulL, R. Organic evolution. New York: Macmillan Company, 1927.

LYELL, C. Principles of geology, being an attempt to explain the former changes of the Earth's surface, by reference to causes now in operation. London: John Murray, 183o. t. 1.

Principles of geology, being an attempt to explain the former changes of the Earth's surface, by reference to causes now in operation. London: John Murray, 1833. t. 3.

Lydekker, R. Geographical history of mammals. Cambridge: Cambridge University Press, 1896.

MAYr, E. O desenvolvimento do pensamento biológico: diversidade, evolução e herança. Brasília: Editora da $\mathrm{UnB}, 1998$.

Marsh, O. Introduction and succession of vertebrate life in America. Nashville: American Association for the Advancement of Science, 1877 .

. Polydactyle horses, recent and extinct. The American Journal of Science and Arts, 17, 3, p. 497-505, 1879 .

. Dinocerata: a monograph of an extinct order of gigantic mammals. Washington: Government Printing Office, 1886.

Mason, F. (Ed.). Creation by evolution: a consensus. New York: Macmillan \& Company, 1928.

Matthew, W. Climate and evolution. Annals of the New York Academy of Sciences, 24, p. 171-318, 1915.

Morgan, T. A critique of the theory of evolution. Princeton: Princeton University Press, 1916. 
Ortmann, A. Tertiary invertebrates. In: Sсотt, W. (Ed.). Reports of the Princeton University expeditions to Patagonia 1896 - 1899, paleontology I - part 2 [1901-1906]. Princeton: Princeton University Press, 1901 a. v.4, p. 48-332.

. The theories of the origin of the Antarctic faunas and floras. The American Naturalist, 35, p. 139-42, $1901 b$.

. Crustacean of southern Patagonia. In: Sсотт, W. (Ed.) Reports of the Princeton University expeditions to Patagonia 1896 - 1899, part 2 - zoology [1905-1911]. Princeton: Princeton University Press, 1911. v. 3, p. $635-67$.

Osвorn, H. The geological and faunal relations of Europe and America during the tertiary period and the theory of successive invasions of an African fauna. Science, 11, 276, p. 561-73, 1900.

. The age of mammals in Europe, Asia and North America. New York: Macmillan Company, 1910.

. Biographical memoir of Joseph Leidy. NationalAcademy of Sciences: Biographical memoirs, 7, p. 33996, 1913.

. Biographical memoir of Edward Drinker Cope (1840-1897). National Academy of Sciences: Biographical memoirs, 13, p. 127-317, 1929.

OwEn, R. On the Archaeopterix of von Meyer, with a description of the fossil remains of a long-tailed species, from the lithographic stone of Soloenhofen. Philosophical Transactions of the Royal Society of London, 153, p. 33-47, 1864 .

Parkinson, J. Organic remains of a former world. London: Sherwood, Neely \& Jones, 1811. v. 3.

Phillips, J. Figures and descriptions of the palaeozoic fossils of Cornwall, Devon, and West Somerset. London: Longman, Brown, Green \& Longmans, 1841.

Podgorny, I. \& Lopes, M. El desierto en una vitrina: museos e historia natural en la Argentina, 1810-189o. Ciudad de México: Limusa, 2008.

RAINGER, R. An agenda for antiquity: Henry Fairfield Osborn \& vertebrate paleontology at the American Museum of Natural History, 1890-1935. Tuscaloosa: Alabama Press, 1991.

. The rise and decline of a science: vertebrate paleontology at Philadelphia's Academy of Natural Sciences, 1870-1900. Proceedings of the American Philosophical Society, 136, 1, p. 1-32, 1992.

Romer, A. Man and the vertebrates. Chicago: Chicago University Press, 1960. v. 1.

RuDWICK, M. Bursting the limits of time: the reconstruction of geohistory in the age of revolution. Chicago: Chicago University Press, 2005.

.Worlds before Adam: the reconstruction of geohistory in the age of reform. Chicago: Chicago University Press, 2008.

Ruse, M. The darwinian revolution: rethinking its meaning and significance. Proceedings of the National Academy of Sciences, 106, 1, p. 104,-7, 2009.

Schindewolf, O. Basic questions in paleontology: geologic time, organic evolution, and biological systematics. Chicago: Chicago University Press, 1993.

Sсотт, W. On the osteology of the poebrotherium: a contribution to the philogeny of the tylopoda. Journal of Morphology, 5, p. 1-78, 1891.

. (Ed.). Reports of the Princeton University expeditions to Patagonia 1896 - 1899, paleontology I - part 2 [1901-1906]. Princeton: Princeton University Press, 1901.

. Reports of the Princeton University expeditions to Patagonia 1896 - 1899. v. 1: Narrative of the expeditions, geography of southern Patagonia. Princeton: Princeton University Press, 1903.

. (Ed.) Reports of the Princeton University expeditions to Patagonia 1896 - 1899, part 2 - zoology [19051911]. Princeton: Princeton University Press, 1911.

. A history of land mammals in the western hemisphere. New York: Macmillan, 1913.

Sedgwick, A. [Review of] Vestiges of natural history of creation (1845). The Edinburgh Review or Critical Journal, 82, p. 1-85, 1845 . 
Simpson, G. The meaning of evolution. New Haven: Yale University Press, 1949.

Horses: the story of the horse family in the modern world and through sixty million years of history. New York: Oxford University Press, $195^{1 .}$

Discoverers of the lost world. New Haven: Yale University Press, 1984a.

Tempo and mode in evolution. New York: Columbia University Press, 1984,b [1944].

WAGNER, A. An excerpt from tortoises and saurians from litographic limestone. In: WeIshampeL, D. B. \& White, N. M. (Ed.). The dinosaurs papers 1676-1906. Washington: Smithsonian Books, 2003 [1861]. p. 271-5.

WANG, Y. et al. Fossil horses and carbon isotopes: new evidence of Cenozoic dietary, habit and ecosystem changes in North America. Palaeogeography, Palaeoclimatology and Palaeoecology, 107, p. 269-79, 1994.

Weishampel, D. B. \& White, N. M. (Ed.). The dinosaurs papers 1676-1906. Washington: Smithsonian Books, 2003.

WheweLL, W. [Review of] Principles of geology, being an attempt to explain the former changes of the Earth's surface, by reference to causes now in operation. By Charles Lyell, Esq. F. R. S. Professor of Geology in King's College, London. The Quarterly Review, 47, p. 103-32, 1832.

Wortmann, J. Psittacotherium, a member of a new and primitive suborder of the Edentata. Bulletin of the American Museum of Natural History, 8, p. 259-62, 1896.

Zitté, K. Textbook of palaeontology. London: Macmillam, 1900.

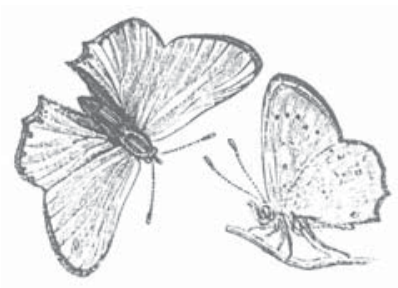

